\title{
Understanding Bike-Sharing Acceptability and Expected Usage Patterns in the Context of a Small City Novel to the Concept: A Story of 'Greek Drama'
}

\author{
Alexandros Nikitas ${ }^{\text {a }}$ \\ ${ }^{a}$ Department of Logistics, Operations, Hospitality and Marketing, Huddersfield Business School, \\ University of Huddersfield, Queensgate, HD1 3DH, Huddersfield, UK
}

\begin{abstract}
Developing initiatives that allow societies to embrace more sustainable travel behaviour patterns is a prerequisite for creating more livable urban futures. Bike-sharing, a measure designed to inspire modal shift from short car-trips, despite its recent exponential growth, is still understudied. This paper discusses a quantitative survey of 640 responses examining road users' attitudes towards bike-sharing and its possible introduction to Drama, a small Greek city resembling many others in terms of size, transport culture and socio-economic characteristics, which has never been exposed to a similar intervention. Most of the respondents recognised that bike-sharing is a mode with pro-environmental, cost-effective and health-improving qualities and the potential to promote a greener identity for the city. Evidence is provided that people would support a bike-sharing investment even in cases where the frequency of their current bicycle use and the regularity with which they intend to use an eventual scheme is low. Age, gender, the primary factor for modal choice, its perceived effectiveness in reducing traffic congestion and their usage expectations were all factors influencing the respondents' acceptability of such an introduction. The lack of cycling infrastructure and road safety concerns were identified as possible usage barriers but the prosocial potential of bike-sharing combined with policy efforts to create a more pro-cycling culture could outweigh them. The present analysis suggests that bike-sharing can go beyond, what is typically regarded as its primary function, that of a last-mile solution for metropolitan areas, and be a publicly acceptable investment for smaller cities.
\end{abstract}

Keywords: Bike-Sharing; Public Bicycles; Shared Use Mobility; Cycling; Sustainable Transport; Attitudes and Public Acceptability.

\footnotetext{
Tel. +44 (0)1484 471815

E-mail: a.nikitas@hud.ac.uk
} 


\section{Introduction}

A car-dominated transportation has been the foundation of urban development on a worldwide scale for decades now. This is a foundation that despite its merits, has been associated with severely adverse effects on the grounds of social, environmental and economic sustainability. The approach for alleviating these is multidimensional and requires input from a wide spectrum of stakeholders and actors, and must include technological innovation, changes in the physical infrastructure and land use, and social, cultural, and institutional changes (Vergragt and Szejnwald Brown, 2007). Promoting a more resourceefficient travel behaviour can be achieved via a variety of 'stick' and 'carrot' measures to tug and tempt people out of their cars, respectively (Kenyon and Lyons, 2003). One of the latter measures is the shared use of mobility resources on an 'as-needed' basis.

Bike-sharing (or public bicycles) is a characteristic example of these shared use mobility mechanisms and one that effectively brings together some of the better qualities that active transportation and public transit have to offer. Bike-sharing refers to a short-term bicycle rental service for inner-city trips that provides bikes at special hire stations or at any available bicycle rack within their catchment area if the system is GPS-based and thus stationless. Bike-sharing has been introduced thus far mostly in large cities, primarily for extending the reach of public transportation to final destinations or as DeMaio and Gifford (2004) quote 'to make it easier for commuters to use a bicycle on the last leg of their public transport journey'. Shaheen et al. (2010) summarises the potential benefits of bike-sharing as flexible mobility, emission reductions, physical activity benefits, reduced congestion and fuel use, individual financial savings and support for multimodal transport connections. These benefits nevertheless, especially the pro-environmental ones, are difficult to measure and to be quantified per se. As Pucher et al. (2010) suggested bicycling and its positive impacts have increased in cities that have implemented bike-sharing programmes but these results reflect simultaneously the impact of improvements in bicycling facilities implemented at the same time as the bike-sharing programmes.

On the other hand, problems usually associated with bike-sharing include: i) systematic underuse, ii) vandalism and theft, iii) complicated planning procedures, iv) sluggish or overambitious scheme expansion usually referring to station-based and station-less systems respectively, v) a one-bike-fits-all business model which may not be ideal for all populations, vi) strict cycling regulations including compulsory helmet use for some countries (e.g. Australia) that make schemes impractical or at least reliant to a supporting rent-a-helmet mechanism, vii) political friction if local authorities (or residents) are unwilling to forsake street parking space for bike stations, viii) road traffic safety concerns generated by the coexistence of bicycles in a heavily car-dominated environment but also the pedestrians versus bicycles narrative in mixed usage situations and ix) lack of adequate cycling infrastructure (e.g. bike lanes, cycle paths, parking racks) that could complement and promote a bikesharing scheme.

The most distinctive function of public bicycles however is the very concept of 'sharing'. According to this, individuals use bicycles when they need them without the costs and responsibilities associated with bicycle ownership (Shaheen et al., 2010). By addressing these ownership-oriented responsibilities, bike-sharing programmes encourage cycling providing hassle- and maintenance-free bicycle access that enables individuals who may not otherwise use bicycles (e.g. tourists or individuals who do not own a bicycle) to enjoy cycling benefits (Shaheen et al., 2012a). This 'freedom' combined with the fact that public bicycles do not obey to any fixed time schedules or routing patterns gives them a state of flexibility and independence uncommon to conventional public transport alternatives (Nikitas et al., 2014). 
Bike-sharing as a new 'exciting' mode is, according to Shaheen et al. (2013), also drawing new populations to bicycling, which in theory has the capacity to reduce problems linked with car over-use and support healthier lifestyles (Shokoohi and Nikitas, 2017). Goodman et al. (2014), actually makes the case that the introduction of bike-sharing systems is one way in which cycling may become normalised in low-cycling settings. This is because bike-sharing can be viewed as a powerful (and in some cases even iconic) on-street reminder 'advocating' that cycling is actively supported by local policy-makers. Thus the definition of bike-sharing, that will be adopted by this study, is describing it as 'a scheme referring to the provision of affordable short-term access to locally branded bicycles on an 'as-needed' basis that could extend the reach of public transit services to final destinations and be a door-opener for increased bicycle usage'.

Despite the potential of bike-sharing and despite 1573 schemes already operating and 402 others 'in planning' or 'under construction' (Meddin and DeMaio, 2018) in more than 50 countries worldwide, its impact has not been fully documented. There is a lack of evidence on existing schemes on whether they achieved their objectives. Ricci (2015) suggests that evidence on the positive impacts of bike-sharing schemes is still fragmented; there is evidence that users get some beneficial impacts but the user base is small and not socially diverse. Research is needed to better understand how these systems are affecting the transportation eco-system and their particular role in current and future planning. Furthermore, Fishman (2016) reports that there is a paucity of research with large numbers of people who are not bike-share users despite the fact that these studies are of critical importance to bike-sharing user growth. Thus, understanding how non-users 'value' bikesharing and how they perceive or eventually materialise its potential is a timely and meaningful research topic.

Also while several studies exist on how bike-sharing schemes are changing mobility in bigger cities across the globe, few studies have looked at the dynamics of these schemes in smaller cities (Caulfield et al., 2017). The aim of the present study is to examine public attitudes to bike-sharing and its eventual introduction in a small European city with low bicycle usage rates and no previous exposure to shared use mobility initiatives. The paper intends to: i) identify and put into context the significance of attitude and norm orientations of the potential bike-share users and non-users in cases when policy seeks to introduce it, not as a last-mile solution for a metropolis, but in a smaller city where such a system could be a 'novel' concept and ii) identify existing barriers that could make people reluctant to use or even approve such a scheme. For this reason, the study was conducted in a city with a size, an economy and a socio-demographic profile not dissimilar with that of many small Greek, Balkan and South European cities. This local case study choice potentially maximises the extent to which the results of this work can be generalised into a wider context.

Hereafter, the paper provides an introduction of the city where the study was conducted, a description of the chosen methodology, a systematic analysis of the results, a discussion of the main findings, study limitations and complementing research and ends with a conclusions and policy recommendations section.

\section{Local case study: the city of Drama}

Drama is a city in North East Greece with a population of 58,944 residents. It is the economic centre and capital of the regional unit of Drama, which belongs to the East Macedonia and Thrace region. Drama is located $670 \mathrm{~km}$ north of Athens and $158 \mathrm{~km}$ from Thessaloniki, Greece's second largest city. The closest sea port and airport are located in Kavala and Chrisoupolis $37 \mathrm{~km}$ and $68 \mathrm{~km}$ away respectively. Until recently, the economy of the city 
depended on its paper and textile-clothing industries. However, during the last two decades, well before the austerity crisis hit Greece, these manufacturing businesses have either ceased their operations or moved across the border to the neighbouring and much cheaper Bulgaria. This has affected adversely the local economy reducing significantly employment opportunities. The Gross Domestic Product (GDP) per person in Drama is $€ 10,842$ (Hellenic Statistical Authority, 2018). For comparison, in 2011 the average GDP per capita for the European Union was $€ 25,100$ but the GPD per capita for the smaller cities of the nonmetropolised regions in South Europe and Eastern Europe was much closer to that of Drama (Eurostat, 2018).

Despite its small scale, during peak-hours, Drama has road traffic congestion issues. Currently petrol-fuelled buses provide the only public transport services available; however these are used almost exclusively by students and older people. Bicycle use has been growing slowly during recent years because of its pro-environmental profile and low-cost to use. Nonetheless, cycling is not yet established as a mainstream travel option for the city; this could be due to the lack of investment on bicycle infrastructure and limited political support (until lately) to promote cycling as a legitimate modal choice over car.

Introducing a bike-sharing scheme, consisting of, at least in its initial form, 50 to 60 bicycles in three to five docking stations, has been in the City's transport agenda for the last few years. This is a low-cost investment costing no more than $€ 100,000$ that can be fully funded by the 'Green Fund' resources of the Greek Ministry of Environment, Energy \& Climate Change (Prasino Tameio, 2013). Developing a sustainable bike-sharing program according to Zhang et al. (2015) can be viewed as a crucial political achievement and a means of positive political branding and image-making. Identifying possible barriers that could reduce the public acceptability of a bike-sharing scheme and understanding its potential for generating modal shift, would enable the policy-makers to make an evidence-based decision regarding its feasibility. Examining the attitudes of Drama's road users and taxpayers on cycling, bike-sharing and its suitability for Drama was thus a process for producing impactful transport innovation reflecting the actual needs (and plans) of the city.

\section{Research methodology}

A primarily quantitative survey was employed to identify attitudes towards bicycle usage, bike-sharing and its potential to succeed in Drama. A questionnaire was administered containing 19 questions organised in four thematic parts referring to: the respondents' general travel behaviour choices; their views on cycling; their attitudes towards bike-sharing and its suitability for the city; and their demographic characteristics. Two of these questions, however, contained 12 and eight sub-questions respectively. Five-point Likert-scales were used to record responses varying from 'strongly agree' to 'strongly disagree'.

Financial incentives and survey introduction notes have been reported to produce consistent improvements in response rates, and therefore both were applied in this study. The incentive was an entry into a prize-draw for a free bicycle and 20 gift vouchers. The introduction of the questionnaire 'pre-notified' the research project, offering a definition of the term 'public bicycles' and discussing why completing the survey was a meaningful and timely task for the respondent. The definition chosen referred to public bicycles as those bicycles that one can access in central points of a city in rental stations (or via mobile apps) for short-term use usually for a small cost'. The introduction of the survey also informed readers that the survey was for an academic study but the results could be also used to inform the local authority about how the residents of Drama felt about a potential introduction of a bike-sharing scheme in their city. 
Other information provided in the introduction note stated that a small scheme of 50-60 bicycles, could cost closely to $€ 100,000$ and is an investment usually funded by the National budget and maintained by the City, a scheme sponsor or/and the contributions of its users via a fee scheme. No specific fee or annual subscription rate estimations were provided to avoid a price-specific bias since the city actively explores the potential of the scheme being free for users, with operational costs covered entirely by a sponsor that will be advertised on the bikes and on the city's billboards ${ }^{1}$. This 'intention' was not disclosed to the survey respondents since this plan is not yet entirely guaranteed but more importantly because the author wanted the bike-sharing scheme idea to be treated not as a 'gift' from the local authorities that would most likely be welcomed, and thus affect acceptability rates, because of its 'free' nature, but as a potential legitimate travel alternative that could cost something similar to other public transport services so that it could be evaluated more 'fairly' by those responding to the questionnaire.

There were no questions referring to a specific hypothetical scenario of a detailed public bicycle programme reflecting the intentions of the local government or the ideas of the researcher about the 'right' solution in terms of positioning and operating the system across the city. This was an intentional feature of the study so that there would not be any bias referring to scheme geographical or operational specifics, especially when these have not been agreed or closely defined yet. On the contrary, the survey contained a question where people could choose through a long list of options the three most important, according to them, transport destinations of Drama that could eventually be hosting the first stations of such a scheme. The latter results are not discussed herein but could inform local policymaking if a bike-sharing investment goes forward.

The questionnaire was available to the public of Drama in an online form and via hard copies $^{2}$. The online survey was accessible through the webpage of the Municipality of Drama and was disseminated electronically through social media, while paper-based questionnaires were posted together with the City's water and sewage bill letters to 3000 households. Hard copies of the questionnaire were also available next to specially designed collection boxes clearly indicating the reason for their availability located in the City Hall's reception, the customer service office of the Municipal Enterprise for Water Supply and Sewerage (D.E.Y.A.D.), the Citizens' Service Centre of the City (K.E.P.) and the Local Centre for Labour Unions (EY.K.). The collection boxes were monitored in a daily basis. The addresses for the postal survey were randomly chosen from D.E.Y.A.D. administrators and were distributed evenly between the different parts of the city, so that the sample would be more representative in geographical terms.

The sample consisted of 640 useable responses; 257 online survey and 383 postal responses. In addition, there were also 31 online and 40 postal partially completed returns that were excluded from the analysis, since the full completion of the questionnaire was a prerequisite for inclusion in the process. The differences between the responses of the postal and the online survey in terms of the attitudinal findings were marginal enabling the use of the total sample for the statistical analysis that follows.

\footnotetext{
${ }^{1}$ This is a strategic approach that has been inspired (and therefore is viable) by the recently established bike-sharing scheme in the neighbouring city of Kavala, a scheme of similar size with the one intended for Drama, where the costs of using the bikes are entirely covered by a sponsor.

${ }^{2}$ This dual approach was decided since this study was aiming to get a sample size that could be representative of Drama's population by maximising data collection opportunities. The empirical knowledge and prior experience of the author about studying attitudes in Drama was suggesting that neither of the two options could solely provide a sample size reflecting the needs of the study since: i) many people in Drama and especially people aged 50 and over are not particularly engaged with internet activities and ii) due to lack of large Universities in Drama there is not yet a research-friendly culture established to allow for an academic-driven postal survey to have response rates comparable to surveys that run in other cities.
} 


\section{Results and analysis}

The results are grouped according to the four thematic parts in which the questionnaire was organised: the respondents' demographic characteristics; their general travel behaviour choices; their views on cycling; their attitudes towards public bicycles and their suitability for the city of Drama.

\subsection{Demographics}

Identifying the profile of the sample in terms of its demographic characteristics is a tool for facilitating more meaningful analytic comparisons and identifying the potential of the sample to be representative of a wider population. Table 1 summarises the collected demographic characteristics of the sample.

Table 1. Sample's demographic profile

The gender split of the sample was in line with that of the Greek population in general (49.2\% male, $50.8 \%$ female) and that of the region's population in particular (49.3\% male, $50.7 \%$ female) as these were recorded by the last Greek Census (Hellenic Statistical Authority, 2018). The results about the respondents' type of household suggest that very few lived on their own. 'Sharing a roof' primarily reflects family responsibilities but it could be also attributed, to a certain degree, to the Greek financial crisis and the higher cost of living in single households. The respondents were in general willing to report their monthly income; only $15.5 \%$ of the sample did not share this information. Almost two thirds of the respondents lived in households earning less than $2,000 €$ per month; this is representative of the current economic situation in Drama.

The two age groups that were most likely to respond to the survey were the people aged 30 to 39 and 40 to 49 . Respondents aged 20 to 29 were not very likely to answer via a hard copy; the number of their online responses were three times as many. It can be hypothesised that they were not likely or willing to reply on behalf of their household when they lived with their parents; people aged 40 to 59 on the other hand were responsible for $58 \%$ of the hard copy responses. Only $5 \%$ of the sample referred to people aged 60 and over while the share of them for the region of Eastern Macedonia and Thrace is 27.1\% (Hellenic Statistical Authority, 2018). Considering that older respondents were the ones most likely to self-report in this study that they never use a bicycle and according to Nelson et al. (2007) are the people less likely to be physically active, one can hypothesise, that this was the age group most likely to be distant to the attitude object (i.e. bike-sharing). The under-representation of people over 60 is consistent with the findings of other researchers on bike-sharing or cycling in general (e.g. Shaheen et al., 2012b and Pucher et al., 2011 respectively). In general, there is still a lack of participation by older people in efforts trying to shape or introduce transport innovation (Sochor and Nikitas, 2016). As a whole, recent research provides evidence that age could be a significant predictor of bike-sharing membership (Fishman et al., 2015).

\subsection{Travel norms}

In order to build up an understanding of the respondents' daily travel experiences and preferred commuting options, data were collected about levels of driving licence holding, frequency of using different transport modes, travel choice for commuting to work/most frequent destination, the reason for choosing a travel mode over others and frequency of facing traffic congestion. Table 2 provides a synopsis of these results. 
Overall, people were very likely to hold a driving license and far more likely to drive than cycle. Only $19.3 \%$ of the respondents were regular cyclists (i.e. people cycling 'daily' or 'few times a week'). Even fewer (4.8\%) people self-reported going to work or their most frequent destination by bicycle. These results confirm that bicycle usage is currently low in Drama. Thus, a strict analysis focusing solely to respondents cycling was limited due to the small number of cyclists within the sample. Nonetheless, this is not hindering the potential of this work to be impactful since as Fishman (2016) recognised, via a thorough bike-sharing literature review, studies looking at general public samples could be of critical importance to bike-share user growth.

\section{Table 2. Travel norms}

A chi-squared analysis set to examine the relationship between monthly household income and regularity of using a bicycle gave no statistically significant results $\left(\chi^{2}=8.129 ; \mathrm{df}=6 ; \mathrm{p}\right.$ $=0.229$ ). This means that bicycle usage as it stands today in Drama does not depend on the citizens' financial situation to the degree that it could have been hypothetised because of the Greek financial crisis; so cycling is not necessarily a mode for people on low incomes.

Table 3 summarises the results directly referring to bicycle ownership and the way with which the respondents use bicycles. The results suggest that cycling is still not treated as a 'real transport alternative' but more as a recreational activity.

Table 3. Bicycle ownership and type of usage

\subsection{Attitudes to cycling in general}

The next two sets of results refer to the respondents' general attitudes towards the 'value' of cycling as a transport mode and to their willingness to approve investments promoting cycling. These results are presented in Table 4 and Table 5 respectively.

Table 4. Attitudes towards bicycles and cycling in general

The respondents believed that cycling is a low-cost, sustainable, enjoyable and healthy travel option with a strong potential to reduce road traffic congestion. The majority of the respondents suggested that bicycling was a good travel alternative to car for inner-city trips. A significant (but still minority) share of the respondents considered cycling as an unsafe and time-consuming mode; as a consequence the mean support for the two statements, as reported in Table 4, was marginally negative.

Table 5. Attitudes towards promoting cycling in Drama

The respondents favoured cycling-related investments. They were positive towards the creation of more cycling-oriented infrastructure in terms of bicycle roads and facilities for parking bicycles. Most of them were also supportive of the notion that cycling should be the key object in a promotional campaign referring to sustainable city transport, which is significant since news media is a primary source of information that can reinforce the attitudes of a community towards cycling (Rimano et al., 2015). More importantly however, the respondents were positive towards the eventual introduction of a public bicycle programme in Drama. In absolute numbers, $87 \%$ of the respondents agreed or strongly agreed with the notion that bike-sharing should be introduced in Drama; only $2.8 \%$ disagreed or strongly disagreed and $10.2 \%$ were neutral to this proposition. 


\subsection{Attitudes to bike-sharing}

These results reveal the public attitudes towards bike-sharing and its eventual suitability for their city. The respondents, in general, viewed bike-sharing positively since they recognised a number of potential societal (or pro-social) benefits ${ }^{3}$ from the implementation of such a programme. Table 6 summarises these results.

Table 6. Attitudes towards public bicycles and their introduction

The vast majority of the respondents agreed that bike-sharing is an environmentally friendly transport mode that could potentially help in reducing road traffic congestion, complement public transport, offer inexpensive travel, promote health and wellbeing, make cycling a more popular travel choice and reduce people's reliance on automobiles. However, perhaps the strongest finding, directly referring to the public acceptance of an eventual scheme, was people's disagreement to the notion that 'public bicycles constitute an investment that they would not like to see being materialised'. In absolute numbers, $86.5 \%$ of the respondents disagreed or strongly disagreed with this notion; only $5.1 \%$ agreed or strongly agreed and $8.4 \%$ were neutral respectively.

The respondents self-reported relatively high levels of potential usage. In this case, chisquare analysis indicates that there are statistically significant differences between the potential frequency of using an eventual scheme between people with lesser incomes and people with higher incomes. People living in households earning less than 2,000€ were more likely to self-report an intention to use frequently the scheme than people earning more than that and people not wanting to provide financial information $\left(\chi^{2}=23.581\right.$; $\left.\mathrm{df}=15 ; \mathrm{p}<0.1\right)$. Other studies found income to be a significant predictor of bike-share membership but in different way. A dual study in Melbourne and Brisbane suggests that higher annual income increases the odds of membership to a public bicycle programme (Fishman et al., 2015) while a survey referring to the London's Barcleys Cycle Hire (now Santander Cycles) found its users to be significantly wealthier than the general London population (Transport for London, 2010). It should be noted, nonetheless, that residents in London's highly-deprived areas did use the scheme when this extended outside of central London to cover some of London's poorest areas; something indicating that the scheme was not exclusively used by affluent commuters (Goodman and Cheshire, 2014). However, comparing membership conditions referring to London and Melbourne with those of a much smaller and less affluent city like Drama might not be straightforward; thus the importance of studying bike-sharing for the less mainstream context of a small city.

Another result, referring to the eventual frequency of adopting bike-sharing as a travel mode, was that the people who self-reported a modest level of bicycle usage (i.e. 'once a

\footnotetext{
${ }^{3}$ Some of the items examined in this section referring to the likely benefits of bike-sharing, like possible road traffic congestion reductions, have never or rarely been directly associated with the introduction of bike-sharing in isolation from other factors before. Nevertheless, there were evaluated as important inclusions in the present survey since this is a study aiming to explicitly explore attitudes referring to the public acceptability of a possible future scheme. Perceptions about the likely qualities of a study object may sometimes have a similar or bigger impact on individual acceptance than quantified correlations recorded by the literature and earlier practice with people being irrational decision-makers. The content of the survey and the language used tried to neutralise and minimise any potential biases that could mislead respondents though. For instance, the survey's introduction note presented bike-sharing not as a 'transport saviour' but as a potential city investment possibly linked with some financial burdens. Also although most question items negotiated bike-sharing by looking respondents to evaluate a positive characterisation about it (e.g. bike-sharing promotes health and well-being) the most critical item examining the overall acceptance of bike-sharing was framed in a sceptic form (i.e. I would not like to see a public bicycle investment getting realised) for balance reasons.
} 
week' or 'once a month') were more likely than regular cyclists and people 'rarely' or 'never' cycling to report that they intend to use bike-sharing at least occasionally. This finding means that this is the group of road users that policy-makers could be targeting first when they want to introduce a new bike-sharing scheme that has a strong potential to have a concrete start-up audience. This was a statistically significant result $\left(\chi^{2}=14.529 ; \mathrm{df}=4 ; \mathrm{p}<0.05\right)$.

Results aiming to record the way with which people could be using a bike-sharing scheme (i.e. as main, alternative or leisure-related travel option) were also collected. More than half of the respondents self-reported that they would use bike-sharing as a primary or secondary alternative to their main travel option. The author also examined the degree with which people would be adopting cycling in their daily routine in case that the local government made focused efforts to provide infrastructure and service improvements such as the implementation of a bike-sharing programme to support bicycle usage. The participants responded to this hypothetical pre-condition very positively. Table 7 summarises these results.

Table 7. Attitudes responding to the hypothetical introduction of bike-sharing

Looking into the reasons that made some respondents reluctant to cycle, in general, and potentially to bike-share, in particular, was another theme of the study. The respondents were asked to choose from a list one or two factors (the most relevant to them) that could make them hesitant to adopt a more pro-cycling travel behaviour. The main reasons for this reluctance are primarily associated with the lack of bike-friendly infrastructure and the feeling that road safety for cyclists is limited. These two factors are interrelated since infrastructure accommodating the needs of cyclists could improve road safety conditions both in real terms but also in the way people perceive these conditions. Figure 1 provides graphical information about the participants' responses for this theme.

Fig. 1. Reasons for not cycling and not being willing to eventually bike-share.

A detailed spatial analysis was beyond the scope of the present study. Nevertheless, a generic observation reflecting the postal survey sample (where the geographical allocation of responses was possible) can be presented. In general, people living closer to the city centre or to key areas (e.g. the city's hospital) that could eventually host a bike-sharing station were more likely to self-report a potential for 'high' bike-sharing usage than people living in more remote areas. This is in line with past research, for example the study in Montreal from Fuller et al. (2011), suggesting that the proximity of residential addresses to docking stations appears to have a powerful influence over propensity to bike-share.

\subsection{Modelling Results}

Further to the descriptive analysis, a statistical model (Table 8) was developed to quantify the relationship between attitudes towards the acceptability of bike-sharing and variables representing some of the survey elements that could explain this relationship and identify how close and well-determined it is. Ordinal regression was employed since it is an appropriate generic model for the empirical analysis of any ordered, categorical dependent variable, which in this case represented the attitude towards the implementation of bikesharing in the city (i.e. compliance to the notion that public bicycles should be introduced in Drama). Various models were tested, using a combination of independent variables, but only the best fit, a model referring to statistically significant results, is presented. The model uses as independent variables: the expected type of bike-sharing usage; the perceived effectiveness 
of bike-sharing in reducing traffic congestion; the primary factor behind modal choice; gender; and age. Two variable categories were used for the model because of the small size of the 'strongly disagree' and 'disagree' groups; thus the binary model presented in Table 8. The first variable category refers to 84 respondents that strongly disagreed, disagreed or were neutral to the introduction of bike-sharing while the second refers to 556 respondents strongly agreeing or agreeing with the introduction of bike-sharing.

Table 8. Ordinal regression model for bike-sharing acceptability

Although, in general, even people not expressing an intention to use an eventual scheme were very likely to support its introduction, 'expected usage norms' seem to have an impact on the acceptability of bike-sharing. The usage themed variable that was employed in the model referred to respondents' expectation of the way with which they would utilise bikesharing if this was introduced. This independent variable produced more robust models than the ones involving the 'frequency of expected usage' variable although the pattern of correlation was very similar; the more frequent the expected use was the more likely people were to support bike-sharing. The model presented in Table 8 used five categories of expected usage types: main mode, main alternative, secondary alternative, only for exercise and joy and no use with the latter as a reference category. The odds of people that selfexpressed their intention to use bike-sharing when available to support its introduction were higher than those of people not planning to use it. People potentially using bike-sharing for utilitarian reasons were more likely to be supportive than those seeing it as a recreational activity. Also people utilising it the most (i.e. as a main mode or main alternative) were more likely to accept bike-sharing than those who listed bike-sharing as a secondary travel alternative.

Since the potential of bike-sharing to be perceived as a pro-social transport intervention from the public was an underpinning theme for this study the model incorporated one of the variables that the survey used to measure this. The best fit was the variable reflecting perceived effectiveness of bike-sharing in reducing traffic congestion. Using a different prosocial variable (i.e., one of the variables linked to attitudes about promoting a greener and more human-friendly city, complementing public transport, making cycling more popular, promoting health and wellbeing, providing an inexpensive travel mode, disengaging people from daily car use), gave similar models to that reported in Table 8. However, using a combination of two, three or four explanatory variables reflecting pro-social themes simultaneously did not produce statistically significant estimate results (due to the high correlation between them). Two variable categories were used in the model to reflect the compliance of the respondents with the notion that bike-sharing could reduce traffic congestion: the first refers to the choices 'strongly disagree', 'disagree' and 'neutral' and the second, which was the reference variable category, refers to the choices 'agree' and 'strongly agree'. This alternative grouping was necessary because of the small size of the two groups with people negatively oriented towards this notion that would have given unreliable results. The odds of people believing that bike-sharing could reduce traffic congestion to accept this measure were 10.870 times higher than those of people that were either negative or neutral to the effectiveness of bike-sharing as a mechanism for reducing traffic congestion $\left(\chi^{2}=40.771\right.$; $\mathrm{p}<0.01)$. Thus identifying the pro-social potential of bike-sharing, in general, and its perceived effectiveness as a traffic reduction mechanism, in particular, could be a strong predictor of the measure's public acceptability.

The main decision-making criterion behind respondents' travel mode choices was also a factor affecting public acceptability. Five variable categories were used referring to reasons primarily based on: cost, comfort, availability, time and environment. The latter was the 
reference category for the independent variable comparisons. With the exception of the results related to time considerations all the results were statistically significant and had a positive sign, meaning that the odds of people choosing their travel mode based on environmental reasons to support the introduction of bike-sharing were lower than those of individuals deciding their travel mode based on another criterion. People assigning cost as their primary factor for their choice of travel mode were the ones most likely to support a bike-sharing scheme, followed by those assigning availability and those assigning comfort. This result does not mean that environmental concerns are not important for road users since recent research (Kim et al., 2017) provided evidence that the perceived value of a public bicycle system is affected significantly by them, but suggests that other factors, usually less acknowledged, are of critical importance too. So in terms of policy-making, although bikesharing's environmental potential should be emphasised in the branding, marketing and communication strategies of an eventual implementation, a cost-related agenda referring to the value of bike-sharing as an affordable modal choice, especially for those in need of a lowcost alternative, could be an equally important dimension that these strategies need to incorporate. Also since people seem to be influenced by cost considerations, the low-cost investment necessary for introducing, running and maintaining a bike-sharing scheme (when compared to other transport interventions) need to be highlighted by local policy-makers.

The odds of female respondents to support the notion that bike-sharing should be introduced in Drama were 2.012 times higher than that of the male respondents $\left(\chi^{2}=5.335 ; \mathrm{p}\right.$ $<0.05)$ although men were already very likely $(84.9 \%)$ to agree or strongly agree to the implementation of a public bicycle scheme. This is a particularly interesting finding since women in general self-expressed a higher probability for not using bike-sharing at all or using it for the recreational purposes only $\left(\chi^{2}=17.194\right.$; $\left.\mathrm{df}=4 ; \mathrm{p}<0.01\right)$ something in line with a body of research clearly suggesting that bike-share members are disproportionally male (Fishman et al, 2015; Goodman and Cheshire, 2014; Kark and Tao, 2016; Pucher et al., 2010; Pucher et al, 2011). This could suggest that women support bike-sharing not because they are more likely to use it but because they genuinely consider it as a scheme with a strong prosocial character. Recent research (Sochor and Sarasini, 2017) about perceptions referring to 'mobility as a service' (which is a similar in principle but more novel concept) indicate that women were significantly more positive to this than men. So perhaps based on this evidence it can be suggested that women tend to be more appreciative of novel transport interventions with pro-social potential than men.

Finally, age, was found to be associated with the acceptability of a bike-sharing scheme. The odds of people aged 60 and over, 50 to 59 and 30 to 39 were considerably higher than that of people aged 29 or younger, although $81 \%$ of these young individuals thought that public bicycles should be introduced in Drama too. The result was not statistically significant for the group aged 40 to 49 . Since people aged 50 and over, and especially the 60+ group, are possibly the individuals least likely to use a bike-sharing scheme, this result suggests that they see this as an investment that although not particularly useful for them, can be good for their city and thus has a pro-social potential. Recent research (Nikitas 2010; Nikitas et al., 2018; Sochor and Nikitas, 2016) actually supports that older people tend to be more supportive of novel (even controversial) transport interventions than younger cohorts if they think that these have a genuine pro-social potential. 


\section{Discussion}

As with any other alternative to car mobility, as Banister (2008) suggests, it is only through the understanding and acceptance by the people that initiatives like bike-sharing will succeed. Within the social sciences, research into the barriers and incentives that motivate particularly urban cycling is burgeoning (Pucher and Buehler, 2012) but has only now started to concentrate in the case of bike-sharing.

This paper aims to frame road user attitudes to bike-sharing in an environment that has no previous exposure to the concept of shared use mobility, which despite bike-sharing's rapid emergence, is still the case for the majority of small or medium sized cities around the world. The concept of the attitude is employed primarily as affecting and reflecting public acceptability, with a particular focus on 'measuring' bike-sharing's perceived pro-social potential. ${ }^{4}$ Public acceptability, which is a good indicator of the potential political adoption and support of a measure at the local level (May et al., 2008) and perhaps a predictor of the eventual usage rate of a scheme, is not always as straightforward as it might be expected for a measure that could be classified as a 'carrot'. Meddin and DeMaio (2018) report as many as 172 public bicycle schemes worldwide that ceased their operations because they either failed to be financially sustainable due to underuse (e.g. Hourbike in Bristol, UK), vandalism and theft (e.g. Wukong Bicycle, China) and aggressive expansion going wrong (e.g. Bluegogo stationless bikes in China and San Fransisco, U.S.) or were replaced by improved schemes (e.g. Styr \& Ställ replaced City Bikes in Gothenburg, Sweden).

The choice of a small and not particularly affluent city with no bicycle-friendly culture resembles a lot of urban and rural-urban environments around the world; especially in South Europe and Balkans. This 'resemblance' enables, to a degree, the generalisation of some key results to a wider context; especially for cities prioritising transport investments of low cost. It could be hypothesised that the vision of introducing and popularising the shared use of mobility and other societal resources and developing a framework for a 'sharing culture' is, more than ever before, a timely need, especially for this part of Europe in light of Cohen and Muñoz (2016) suggestion that cities need to become breeding grounds for a new, circular economy driven by emerging and long-standing sharing activities. This is because South Europe is an area that has been experiencing an extensive financial crisis during the last decade; falling tax revenues and increased spending (especially on bank bailouts) amplified government deficits, while unemployment increased substantially and rapidly forcing countries like Greece and Portugal to adopt austerity policies, including large-scale public sector cuts and reforms in return for financial rescue packages (Karanikolos et al., 2013). This crisis however could perhaps push policy-makers to be more resourceful and supportive of novel interventions in order to keep up with the challenge of providing 'more development' with 'less resources'.

Specific hypotheses each of them reflecting how the respondents view cycling and public bicycles in particular were examined and the majority of them, at least at the aggregate level, provide strong evidence that people hold positive attitudes to bike-sharing and its eventual introduction and assign positive attributes to cycling as 'an activity' and as 'a transport mode' in general. Even the $t$ majority of the people that self-reported a small or no likelihood to ever use systematically bike-sharing agreed with the implementation of a scheme; the likelihood of accepting a scheme was marginally higher for the likely users $\left(\chi^{2}=140.646\right.$; $\mathrm{df}=8 ; \mathrm{p}<$ 0.05). Thus, an eventual introduction of bike-sharing will not be viewed as a measure favouring a particular road user segment over other people that might not use it. This conclusion, together with the overwhelming levels of support to all the survey items

\footnotetext{
${ }^{4}$ However there are survey instruments, especially those referring to respondents' expected usage patterns, where attitudes can be regarded as factors directly referring to intentional travel behaviour (as proposed by Ajzen, 1991).
} 
negotiating the potential effectiveness of bike-sharing in benefiting the society in different fronts indicate that bike-sharing, at least for the case of Drama, has been credited with a strong pro-social potential.

This is important considering that bike-sharing is not ideal for every member of an urban society for various reasons. It is a travel mode that cannot accommodate storage or family needs, may not be a viable choice under bad weather conditions and for long distances, might not be useful for people already owning bicycles and perhaps more importantly its embracement requires physical 'tools' that may exclude mobility-challenged individuals from using it. Since the political support of transport measures is often adversely affected by the perceived lack of public acceptability (Nikitas et al., 2011) knowing about the popularity of bike-sharing among wider audiences than its users (or eventual, in this case, users) could be a key for 'justifying' an investment and 'easing' its implementation.

From a potential usage perspective, despite the fact that currently only one out of five respondents cycle in a regular basis and $41.7 \%$ do not even own a bicycle within their household, their positive attitudes about bike-sharing probably led them to self-report significantly high bike-sharing usage expectations. Specifically, $46.9 \%$ of them reported that they will be using such a scheme at least few times a week while $42 \%$ of them may use the scheme as their main mode or main alternative. Fishman et al. (2013) however reported that most usage rates of bike-share schemes globally vary from around three to eight trips per bicycle per day, but some of them facilitate as few as 0.3 trips per bicycle per day. These rates refer usually to more bike-oriented environments than Drama a city that currently lacks a strong 'pro-cycling culture'. This evidently means that the usage figures 'forecasted' herein may be significantly higher than the real usage rates of an eventual scheme.

Looking beyond social desirability and optimism biases that might have had an impact on the reported hypothetical usage rates, this set of results confirms again that the respondents were in favour of a bike-sharing; over-expectations of usage are typically associated with an intervention that is viewed favourably and tends to have a pro-social dimension. This high public acceptability and the recognition of the measure's pro-social qualities, will probably not decline even if future scheme usage rates are considerably lower than the ones reported herein. Nikitas et al. (2016) described a bike-sharing study in Gothenburg, for the local Styr \& Ställ, that actually supports this hypothesis; although the scheme's approval rates were almost identical to those of Drama (close to 90\%), three quarters of the respondents never used the scheme. High acceptability for bike-sharing thus does not reflect or depend on high usage rates per se but rather represents option value. It should thus be viewed as a trigger for making the introduction of a scheme viable in political terms and not necessarily as a predictor of high or low subscription levels.

Another theme that emerged from the study is that cycling, in general, and public bicycles, in particular, are not perceived by many respondents as legitimate travel modes that could replace short car trips, but rather as opportunities to exercise and have fun in their spare time (i.e. recreational cycling). Cycling is often more common as an exercise or recreational activity than what it is for utilitarian purposes (Moudon et al., 2005) so this result was not entirely unexpected. There are reasons to believe that even if this type of cycling activity will be initially generated by an eventual bike-sharing scheme this could facilitate, on a longerterm, more bike-related commuting. Recent research has indicated that while the effect of bicycle commuting on non-work cycling is somewhat greater than vice versa, both types of cycling positively influence each other over time (Kroesen and Handy, 2014). Because of this bi-directional relationship, any efforts to stimulate cycling in a particular domain may be expected to spill-over to other domains. This means that bike-sharing could be a tool with the potential to forge a more pro-cycling culture for both utilitarian and recreational usage. 
Barriers to bike-sharing, according to the literature, can broadly be divided into two categories; those acting as barriers to bike use generally, such as safety concerns or distance, and secondly those relating specifically to bike-sharing such as docking station location (Fishman et al., 2014). The two most frequently selected reasons by the respondents of the present study for being disinclined to eventually adopt bike-sharing or cycle per se, are the lack of bike-specific infrastructure and the perceived fear that road safety for cyclists is low. It is true that only recently the construction of bike lanes, bike roads and bicycle racks has been initiated in the city of Drama; therefore these specific attitudes are well justified. Actually, in the vast majority of Greek cities the infrastructure for alternative means of transport, and in particular for bicycling, is limited resulting in low usage levels; for example only $0.9 \%$ of the trips in Athens refer to bike rides (Milakis, 2014). Traffic safety concerns have been identified as a key barrier for adopting bicycling universally (Rietveld and Daniel, 2004; Xing et al., 2010) and especially in countries with low rates of cycling and high rates of car use where adequate cycling related investments could be missing (Garrard et al., 2008). This means that the two barriers identified by the present study are highly interconnected especially for the context of countries like Greece.

Similarly, Daley et al. (2007) suggested that themes centred on safety concerns, which have the potential to be important obstacles in adopting cycling, is the lack of cycling infrastructure and low recognition and respect of cyclists' needs by other road users. According to Fishman et al. (2012) lack of contiguous bicycle infrastructure and awareness from motor vehicle drivers has been identified as a key barrier to bicycling, in general, and to bike-sharing, in particular, by relevant studies. This supports the findings of the present article. Broader cycling literature provides various suggestions regarding the influence that limited traffic safety perceptions might have on cycling. Miah et al. (2016) suggested that cycling is still perceived as relatively unsafe and therefore it has yet to be adopted as a real alternative to the private car. The mortality stemming from a bike-car collision has made cycling vulnerable in reality and the perceived risk in streets full of motorised vehicles has deterred travellers from biking (Yang et al., 2015). Horton (2007) suggested that the majority of road users tend to express agreement of some level with the notion that 'cycling on busy roads frightens me'. Parkin et al. (2007) argued that the acceptability of cycling is based, among others, on perceived risk across the different components of a journey. Xing et al. (2018) found that perceptions that bicycling is safe positively correlate with liking it. Galanis et al. (2014) suggested, considering Greek data among others, that there are five basic areas of concern when promoting bicycling in urban areas directly referring to the two highlighted barriers discussed herein: the bicyclists' road and personal safety and the accessibility, convenience and attractiveness of the urban road environment and bicycle infrastructure.

Despite the fact that bicycling has been seriously neglected as a mainstream travel mode, that requires substantial investments by the local authorities of the city in the past, bikesharing was viewed very positively by the respondents. This highlights the vast potential that bike-sharing has to eventually be an integral part of the city's transport future. If the local policy-makers decide to fund infrastructure that supports the needs of cyclists, and therefore improve road safety conditions both in real terms, but also in the way people perceive those, bike-sharing could be eventually a worthwhile investment for Drama or cities like Drama; an investment that could promote a transition to a significantly increased bicycle usage.

This is something that comes across very strongly when comparing the results referring to the way with which the respondents use cycling today with the directly comparable (yet hypothetical) usage results, under the precondition that there would be serious investments on bicycle infrastructure, including a bike-sharing scheme. Apparently, the people that thought they would use a bicycle as their main travel mode in the aftermath of a potential focused infrastructure investment package quadrupled. 
Also when discussing keys to increased bicycle usage and the role that bike-sharing could be playing in this travel behaviour change for Drama, the most basic requirement of all should be noted; people cannot cycle if they do not have access to a bicycle, something referring to many of the study's respondents. Cervero et al. (2009) suggested that the availability of a bicycle in a household is the strongest single predictor of bicycling for transportation. A bike-sharing programme may not be the exact equivalent to owning a bike but could increase access to bicycles through enabling their temporary use, and together with other improvements in bicycling facilities implemented at the same time, similarly with what Puncher et al. (2010) suggested, could increase cycling in the city.

Since previous research shows convenience factors to be important motivators for bikeshare use (Bachand-Marleau et al., 2012; Fishman et al., 2013; Shaheen et al., 2012b) a future bike-sharing scheme should also address issues such as: the location of docking stations and their optimal distribution across the city; the design quality of the bicycles and the stations; and the ease of subscribing to and using the programme.

\section{Limitations and complementing research}

It should be acknowledged that the present study has some limitations. Self-report data may be subject to a number of biases (Paulhus, 1991), especially when they refer to attitudes for a future scheme with a seemingly strong pro-social profile, which is not yet defined in terms of its operational specifics. This could mean that 'accepting' or 'using' bike-sharing might have been 'the right answer' for the respondents even if this was not corresponding to their real intentions or ability to change travel behaviour. Fuller et al. (2013) reported that, for this sort of studies, social desirability bias is of particular concern. Respondents, particularly noncyclists, may have overestimated their shift towards an active mode of transportation in order to be more likeable to the people setting the questions. Humans, according to Sharot (2011) when it comes to predicting what will happen in the future, tend to overestimate the likelihood of positive events, and underestimate the likelihood of negative events. When individual (or societal) decision-makers have some freedom in choosing their probabilistic beliefs, they are often optimistic; they appear to choose beliefs that are biased towards favourable outcomes (Bracha and Brown, 2012). In this case the positive outcome for the respondents could have been the usage of bike-sharing since this would allow them to achieve a more sustainable travel behaviour.

A future research study of a more qualitative character has been already planned from the author for developing a more in-depth understanding of the reasons that make people's attitudes so positive towards a scheme that a lot of them might not even use. A sister surveybased study reflecting bike-sharing attitudes in Gothenburg, Sweden and the success of the local scheme Styr \& Ställ, has been also recently conducted documenting almost identical acceptance rates which validate to a degree the acceptability results of the present work (Nikitas et al, 2016).

\section{Conclusions and policy recommendations}

The paper presented the results of a quantitative survey on bike-sharing public acceptability that was launched in Drama. This is a Greek city which resembles many small cities in South Europe that do not have a bike-sharing programme. Six-hundred-forty fully completed questionnaires were collected and analysed. The respondents believed in general that cycling could be a sustainable, cost-saving, healthy and pleasant activity capable of reducing road 
traffic congestion. The vast majority of them considered that more bicycle-related investments are necessary for the city. More importantly though, only an insignificant proportion of the respondents $(2.8 \%)$ disagreed with the notion that bike-sharing should be introduced in Drama.

Looking beyond social desirability and optimism biases that might have had an inflating effect on the hypothetical usage rates, the results of the study make clear that the respondents were in favour of a bike-sharing scheme recognising its pro-social potential to benefit the environment, the provision of public transport options, people's health, those in need of a low-cost alternative and the city's traffic congestion and image. This public acceptability will probably not decline even if future scheme usage rates are considerably lower since as has been tested by Nikitas et al. (2016) low bike-sharing usage rates do not lead to low public acceptability. Also taking under consideration that, according to Pucher et al. (2011), city size plays an important role in affecting cycling safety (small cities are safer than bigger ones) and the very marginal cost compared to other transport investments for a city similar to Drama's size and economy, this paper concludes with a robust recommendation.

Bike-sharing could go beyond being a first or last-mile solution for the context of bigger sized cities. Bike-sharing may also be suitable for cities as small and as financially restrained as Drama if local authorities actively support the creation of a cycling-friendly culture. Its low cost, in terms of investment and maintenance for the state and fees for its possible users, its potential to provide carbon-free mobility services between key destinations of the city and promote the visions of 'sharing societies' and 'mobility as a service' and the fact that it is viewed favourably even from people not intending to use it can all be reasons for that. Thus bike-sharing could be a complementary piece to public transport in small to mid-sized cities as Martin and Saheen (2014) have suggested that in addition imrpoves the image of the city and increases travel choice for road users.

However small cities could also face considerable, but ultimately treatable challenges, when trying to introduce bike-sharing; they might need to overcome actual low bike-sharing usage rates and support the long-term economic sustainability of a system. So as Audikana et al. (2017) suggested identifying possible target groups and building accountable communication and branding strategies are elements that must be taken into account to improve the performance of smaller bike-sharing systems.

In this respect, the present research makes some recommendations that apply to Drama and to some degree to similar environments for which the concept of bike-sharing is still relatively novel. People cycling modestly (e.g. 'once a week' or 'once a month') could be the main usage-related target group since these individuals tend to be more likely than regular cyclists and people 'rarely' or 'never' cycling to report that they will use bike-sharing. Incorporating, without altering its overall unisex character, some more feminine design features into the scheme could incentivise women, who were more supportive to the introduction of a scheme than men, to become members of a bike-sharing programme. Exploring ways to enhance female participation in bike-sharing schemes is generally recognised by research (e.g. Karki and Tao, 2016) as a critical issue for battling underuse and making sure that there are fewer underserved populations. Using electric bicycles, pedal assist systems, tricycles and other inclusive vehicles and making bike-sharing technologies more easily accessible (e.g. easier pick up and drop off station services) could perhaps enable some individuals, and especially older people, to translate their overwhelming acceptability of bike-sharing to actual usage. This is in line with Strömberg et al.'s (2016) evidence that providing a chance to road users to try specially adapted bicycles, like the ones listed above, can lead them to replace some of their car trips with bicycling. After all since equity aspects are now considered part of the project evaluation procedure (Thomopoulos et al., 2009) designing a genuinely inclusive scheme could be the only way forward. 
Marketing mechanisms and bicycle or station design choices that appeal to young individuals could perhaps motivate them to be more actively engaged with an eventual scheme. Cycling guided tours, educational cycling events and the development of social networks promoting public engagement with cycling and bike-sharing, all activities in line with what Bakogiannis et al. (2017) reported as best practice examples applicable to Greek cities, can help the image of public bicycle programmes. An effort to invest on bike-related infrastructure and road safety improvements for cyclists should be complemented by an awareness campaign about cycling and bike-sharing road safety concerns and a marketing campaign celebrating new bike-friendly investments. This cycling safety re-branding approach directly reflecting the reasons making individuals reluctant to cycle, in general, and bike-share, in particular, could increase bike-share users' numbers. A post-implementation market segmentation analysis, like the one reported by Morton (2017), or an ethnographic user-experience assessment, like the one reported by Berajano et al. (2017), could also identify opportunities for attracting different groups of users that are distinct in terms of their experiences with the scheme, the manner in which they use the scheme, and their behavioural intentions towards the scheme.

Finally, the capacity of bike-sharing to be a low-cost travel alternative, that nowadays may be far less highlighted in comparison with its environmental attributes, should be marketed, branded and communicated equally effectively because cost seems to be a prime criterion behind travel choice that affects acceptability and potentially use. As a whole the scheme's overall potential to be a pro-social transport intervention needs to be emphasised because this is the key to acceptance, and to a lesser degree, since the two are not synonymous, to usage.

\section{Acknowledgements}

The author is grateful for the initial funding support of Mistra Urban Futures and Chalmers University of Technology and the help of Drama's local government and D.E.Y.A.D. Special thanks to Mr Nikitas Michalakopoulos and Mr Georgios Salpistis for their help with data collection.

\section{References}

1. Ajzen, I. (1991). The theory of planned behaviour. Organizational Behaviour and Human Decision Processes, 50, 179-211.

2. Audikana, A., Ravalet, E., Baranger, V., and Kaufmann, V. (2017). Implementing bikesharing systems in small cities: Evidence from the Swiss experience. Transport Policy, 55, 18-28.

3. Bachand-Marleau J, Lee BHY and El-Geneidy AM (2012). Better understanding of factors influencing likelihood of using shared bicycle systems and frequency of use. Transport Research Record, 2314, 66-71.

4. Bakogiannis, E., Kyriakidis, C., Siti, M., and Eleftheriou, V. (2017). Four stories for sustainable mobility in Greece. Transportation Research Procedia, 24, 345-353.

5. Banister, D. (2008). The sustainable mobility paradigm. Transport Policy, 15(2), 73-80.

6. Bejarano, M., Ceballos, L. M., and Maya, J. (2017). A user-centred assessment of a new bicycle sharing system in Medellin. Transportation research part F: Traffic Psychology and Behaviour, 44, 145-158.

7. Bracha, A. and Brown, D. J. (2012). Affective decision making: A theory of optimism bias. Game and Economic Behavior, 75, 67-80. 
8. Cervero, R, Sarmiento, O., Jacoby, E., Gomez, L. and Neiman, A. (2009). Influences of built environment on walking and cycling: Lessons from Bogota. International Journal of Sustainable Transportation, 3(4), 203-226.

9. Caulfield, B., O'Mahony, M., Brazil, W. and Weldon, P. (2017). Examining usage patterns of a bike-sharing scheme in a medium sized city. Transportation Research Part A: Policy and Practice, 100, 152-161.

10. Cohen, B. and Muñoz, P. (2016). Sharing cities and sustainable consumption and production: towards an integrated framework. Journal of Cleaner Production, 134, 8797.

11. Daley, M., Rissel, C. and Lloyd, B. (2007). All dressed up and nowhere to go? A qualitative research study of the barriers and enablers to cycling in inner Sydney. Road \& Transport Research: A Journal of Australian and New Zealand Research and Practice, 16(4), 42-52.

12. DeMaio P. and Gifford, J. (2004). Will smart bikes succeed as public transportation in the United States? Journal of Public Transportation, 7(2), 1-15.

13. Eurostat, (2018). Key to European statistics. See: http://ec.europa.eu/eurostat (retrieved 11/01/2018).

14. Fishman, E., Washington, S., and Haworth, N. (2012). Barriers and facilitators to public bicycle scheme use: A qualitative approach. Transportation Research Part F: Traffic Psychology and Behaviour, 15(6), 686-698.

15. Fishman, E., Washington, S. and Haworth, N., (2013). Bike share: A synthesis of the literature. Transport Reviews, 33(2), 148-165.

16. Fishman, E., Washington, S. and Haworth, N. (2014). Bikeshare's impact on car use: Evidence from the United States, Great Britain and Australia. Transportation Research Part D: Transport and Environment, 31, 13-20.

17. Fishman, E., Washington, S., Haworth, N. and Watson, A. (2015). Factors influencing bike share membership: An analysis of Melbourne and Brisbane. Transportation Research Part A: Policy and Practice, 71, 17-30.

18. Fishman, E. (2016). Bikeshare: A review of recent literature. Transport Reviews, 36(1), 92-113.

19. Fuller, D., Gauvin, L., Kestens, Y., Daniel, M., Fournier, M., Morency, P. and Drouin, L. (2011). Use of a new public bicycle share program in Montreal, Canada. American Journal of Preventive Medicine 41(1), 80-83.

20. Fuller, D. Gauvin, L., Kestens, Y., Morency, P., Daniel, M., and Drouin, L. (2013). The potential modal shift and health benefits of implementing a public bicycle share program in Montreal, Canada. International Journal of Physical Activity and Health, 10(1), 66.

21. Galanis, A., Papanikolaou, A. and Eliou, N. (2014). Bikeability audit in urban road environment: Case study in the city of Volos, Greece. International Journal of Operations Research and Information Systems, 5(2), 21-39.

22. Garrard, J., Rosch, G. and Kai Loc S. (2008). Promoting transportation cycling for women: The role of bicycle infrastructure. Preventive Medicine, 46(1), 55-59.

23. Goodman, A., Green, J. and Woodcock, J. (2014). The role of bicycle sharing systems in normalizing the image of cycling: An observational study of London cyclists. Journal of Transport and Health, 1, 5-8.

24. Goodman, A. and Cheshire, J. (2014). Inequalities in the London bicycle sharing system revisited: impacts of extending the scheme to poorer areas but then doubling prices. Journal of Transport Geography, 41, 272-279.

25. Hellenic Statistical Authority, (2018). Demographic characteristics of Greek population based on the Hellenic Census 2011. See: http://www.statistics.gr (retrieved 01/04/2018). 
26. Horton, D. (2007). Fear of cycling. In Horton, D., Rosen, P. and Cox, P. (ed.) Cycling and Society, Hamphisire: Ashgate Publishing Limited.

27. Karanikolos, M., Mladovsky, P., Cylus, J., Thomson, S., Basu, S., Stuckler, D., Mackenbach, J. P. and McKee, M. (2013). Financial crisis, austerity, and health in Europe. The Lancet, 381(9874), 1323-1331.

28. Karki, T. K., and Tao, L. (2016). How accessible and convenient are the public bicycle sharing programs in China? Experiences from Suzhou city. Habitat International, 53, 188-194.

29. Kenyon, S. and Lyons, G. (2003). The value of integrated multimodal traveller information and its potential contribution to modal change. Transport Research Part F: Traffic Psychology and Behaviour, 6 (1), 1-21.

30. Kim, J., Choi, K., Kim, S. and Fujii, S. (2016). How to Promote Sustainable Public Bike System from a Psychological Perspective?. International Journal of Sustainable Transportation, 11 (4), 272-281.

31. Kroesen, M. and Handy, S. (2014). The relation between bicycle commuting and nonwork cycling: results from a mobility panel. Transportation, 41, 507-527.

32. Martin, E. W. and Shaheen, S. A. (2014). Evaluating public transit modal shift dynamics in response to bikesharing: a tale of two US cities. Journal of Transport Geography, 41, 315-324.

33. May, A. D., Page, M. and Hull, A. (2008). Developing a set of decision-support tools for sustainable urban transport. Transport Policy, 15, 328-340.

34. Meddin, R. and DeMaio P. (2017). The Bike-Sharing World Map. See: http://www. bikesharingworld.com (retrieved 25/01/2018).

35. Miah, S., Kaparias, I., Stirling, D. M., and Liatsis, P. (2016). Development and testing of prototype instrumented bicycle for prevention of cyclist accidents. In Transportation Research Board 95 ${ }^{\text {th }}$ Annual Meeting (No. 16-3977).

36. Milakis, D. (2014). Will Greeks cycle? Exploring intention an attitudes in the case of the new Bicycle Network of Patras. International Journal of Sustainable Transportation, 9(5), 321-334.

37. Morton, C. (2017). Appraising the market for bicycle sharing schemes: Perceived service quality, satisfaction, and behavioural intention in London. Case Studies on Transport Policy (In Press).

38. Moudon, A. V., Lee, C., Cheadle, A. D., Collier, C. W., Johnson, D., Schmid, T. L. and Weather, R. D. (2005). Cycling and the built environment, a US perspective. Transportation Research Part D: Transport and Environment, 10(3), 245-261.

39. Nelson, M. E., Rejeski, W. J., Blair, S. N., Duncan, P. W. and Judge, J. O. (2007). Physical activity and public health in older adults: Recommendation from the American College of Sports Medicine and the American Heart Association. Circulation, 116(9), 1094-1105.

40. Nikitas, A. (2010). Understanding the attitudes of older people to road pricing. University of the West of England, Bristol, UK.

41. Nikitas, A., Avineri, E. and Parkhurst, G. (2011). Older people's attitudes to road charging: Are they distinctive and what are the implications for policy? Journal of Transportation Planning and Technology, 34(1), pp. 87-108.

42. Nikitas, A., Wallgren, P. and Rahe, U. (2014). Public bicycles: how the concept of human-oriented "mobility sharing" technology can influence travel behaviour norms and reshape design education. 16th International Conference on Engineering and Product Design Education Conference "Design Education \& Human Technology Relations", September, Enschede, The Netherlands. 
43. Nikitas, A., Wallgren, P. and Rexfelt, O. (2016). The paradox of public acceptance of bike sharing in Gothenburg. Proceedings of the Institution of Civil Engineers Engineering Sustainability, 169(3), 101-113.

44. Nikitas, A., Avineri, A., Parkhurst, G. (2018) Understanding the public acceptability of road pricing and the roles of older age, social norms, pro-social values and trust for urban policy-making: The case of Bristol, Cities.

45. Parkin J., Ryley, T. and Jones, T. (2007). Barriers to cycling: An exploration of Quantitative Analyses. In Horton, D., Rosen, P. and Cox, P. (ed.) Cycling and Society, Hamphisire: Ashgate Publishing Limited.

46. Prasino Tameio (2013). 'Funding automated bike-sharing systems via the Green Fund. See: $\quad$ http://www.prasinotameio.gr/index.php/el/arhiki/28-anakoinoseis/152xrhmatodotisi-koinoxrhsta-podilata (published at 23/05/2013 and retrieved 20/12/2017).

47. Paulhus, D. L. (1991). Measurement and control of response bias. In Robinson, J. P., Shaver P. R. and Wrightsman L. S. (ed.), Measures of Personality and Social Psychological Attitudes, San Diego, CA: Academic Press.

48. Pucher J., Dill J. and Handy S. (2010). Infrastructure, programs, and policies to increase bicycling: An international review. Preventive Medicine, 50, 106-125.

49. Pucher J., Buehler, R. and Seinen, M. (2011). Bicycling renaissance in North America? An update and re-appraisal of cycling trends and policies. Transportation Research Part A: Policy and Practice, 45, 451-475.

50. Pucher, J., and Buehler, R. (2012). City Cycling. London: MIT Press.

51. Rietveld, P. and Daniel, V. (2004). Determinants of bicycle use: do municipal policies matter? Transportation Research Part A: Policy and Practice, 38 (7), 531-550.

52. Rimano, A., Piccini, M. P., Passafaro, P., Metastasio, R., Chiarolanza, C., Boison, A. and Costa, F. (2015). The bicycle and the dream of a sustainable city: An explorative comparison of the image of bicycles in the mass-media and the general public. Transportation Research Part F: Traffic Psychology and Behaviour, 30, 30-44.

53. Ricci, M. (2015). Bike sharing: A review of evidence on impacts and processes of implementation and operation. Research in Transportation Business \& Management, 15, 28-38.

54. Shaheen S., Guzman S. and Zhang H. (2010). Bikesharing in Europe, the Americas, and Asia: Past, present, and future. Transportation Research Record, 2143, 159-167.

55. Shaheen, S., Martin, E., Cohen, A.P., Finson, R. (2012a). Bikesharing across the globe. In Pucher, P. and Buehler, R. (ed.), City Cycling. London: MIT Press.

56. Shaheen, S., Martin, E., Cohen, A. P., Finson, R. (2012b). Public bikesharing in North America: Early operator and user understanding. Mineta Transportation Institute, San Jose.

57. Shaheen, S., Martin, E. and Cohen, P. (2013). Public bikesharing and modal shift behavior: A comparative study of early bikesharing systems in North America. International Journal of Transportation, 1 (1), 35-54.

58. Sharot, T. (2011). The optimism bias. Current Biology, 21(23), 941-945.

59. Shokoohi, R. and Nikitas, A. (2017). Urban growth, and transportation in Kuala Lumpur: Can cycling be incorporated into Kuala Lumpur's transportation system?. Case Studies on Transport Policy, 5(4), 615-626.

60. Sochor, J. and Nikitas, A., (2016). Vulnerable users' perceptions of transport technologies. Proceedings of the Institution of Civil Engineers: Urban Design and Planning, 169 (3), 154-162.

61. Sochor, J. and Sarasini, S. (2017). More than the sum of its parts? The Finnish public's perspectives on Mobility-as-a-Service and ITS. $12^{\text {th }}$ ITS European Congress, June, Strasbourg, France. 
62. Strömberg, H., Rexfelt, O., Karlsson, I. M., and Sochor, J. (2016). Trying on changeTrialability as a change moderator for sustainable travel behaviour. Travel Behaviour and Society, 4, 60-68.

63. Thomopoulos, N., Grant-Muller, S., and Tight, M. R. (2009). Incorporating equity considerations in transport infrastructure evaluation: Current practice and a proposed methodology. Evaluation and Program Planning, 32(4), 351-359.

64. Transport for London, (2010). Travel in London Report 3. Transport for London, London.

65. Vergragt, P. J. and Szejnwald Brown, H. (2007). Sustainable mobility: from technological innovation to societal learning, Journal of Cleaner Production, 15 (11$12), 1104-\quad 1115$.

66. Xing Y, Handy S, Mokhtarian P. (2010). Factors associated with proportions and miles of bicycling for transportation and recreation in six small U.S. cities. Transportation Research Part D: Transport and Environment, 15, 73-81.

67. Xing, Y., Volker, J., Handy, S. (2018). Why do people like bicycling? Modeling affect toward bicycling. Transportation Research Part F: Traffic Psychology and Behaviour, 56, 22-32.

68. Yang, J., Chen, J., Zhou, M., and Wang, Z. (2015). Major issues for biking revival in urban China. Habitat International, 47, 176-182.

69. Zhang, L., Zhang, J., Duan, Z. Y., and Bryde, D. (2015). Sustainable bike-sharing systems: characteristics and commonalities across cases in urban China. Journal of Cleaner Production, 97, 124-133. 


\section{Tables}

\section{Table 1}

Sample's demographic profile

\begin{tabular}{|c|c|}
\hline Demographic characteristics & Sample's specifics \\
\hline Gender & $\begin{array}{c}\text { Male: } 46.7 \% \\
\text { Female: } 53.3 \%\end{array}$ \\
\hline Age & $\begin{array}{c}<20: 6.3 \% \\
\text { 20-29: } 15 \% \\
\text { 30-39: } 29.1 \% \\
40-49: 28.9 \% \\
50-59: 15.8 \% \\
\text { 60-69: } 4.1 \% \\
>70: 0.9 \%\end{array}$ \\
\hline Type of household & $\begin{array}{c}\text { Single: } 13.8 \% \\
\text { Couple: } 11.4 \% \\
\text { Family (with child): } 53.8 \% \\
\text { Family (parents): } 18.9 \% \\
\text { Sharing flat with others: } 2 \% \\
\text { Other: } 0.2 \%\end{array}$ \\
\hline $\begin{array}{l}\text { Educational } \\
\text { Background }\end{array}$ & $\begin{array}{c}\text { Elementary school: } 1.1 \% \\
\text { Junior high school: } 2.8 \% \\
\text { High school: } 26.1 \% \\
\text { Bachelor (T.E.I.): } 18.0 \% \\
\text { Bachelor (University): } 35.6 \% \\
\text { Master: } 10.9 \% \\
\text { Doctorate: } 2.2 \% \\
\text { Other: } 3.3 \%\end{array}$ \\
\hline Income (household) & $\begin{array}{c}<1,000 €: 26.3 \% \\
\text { 1,001-2,000€: } 37.8 \% \\
\text { 2,001-3,000€: } 12.7 \% \\
\text { 3,001-5,000€: } 1.9 \% \\
>5,001 €: 5.9 \% \\
\text { Do not want to say: } 15.5 \%\end{array}$ \\
\hline
\end{tabular}


Table 2

Travel experience

\begin{tabular}{|c|c|}
\hline \multicolumn{2}{|c|}{ Reported travel behaviour } \\
\hline Travel experience/choice & Respondents answers \\
\hline Licence holding & $\begin{array}{l}\text { Yes: } 86.6 \% \\
\text { No: } 13.4 \%\end{array}$ \\
\hline Frequency of driving a car & $\begin{array}{c}\text { Daily: } 54.5 \% \\
\text { Few times a week: } 16.6 \% \\
\text { Once a week: } 4.8 \% \\
\text { At least once a month: } 1.7 \% \\
\text { Rarely: } 4.5 \% \\
\text { Never: } 17.8 \%\end{array}$ \\
\hline Frequency of being car passenger & $\begin{array}{c}\text { Daily: } 9.2 \% \\
\text { Few times a week: } 26.1 \% \\
\text { Once a week: } 13.3 \\
\text { At least once a month: } 7.7 \% \\
\text { Rarely: } 28.7 \% \\
\text { Never: } 15.0 \%\end{array}$ \\
\hline Frequency of driving a motorcycle & $\begin{array}{c}\text { Daily: } 7.7 \% \\
\text { Few times a week: } 7.0 \% \\
\text { Once a week: } 1.6 \% \\
\text { At least once a month: } 2.0 \% \\
\text { Rarely: } 13.0 \% \\
\text { Never: } 68.8 \%\end{array}$ \\
\hline Frequency of bus usage & $\begin{array}{c}\text { Daily: } 4.4 \% \\
\text { Few times a week: } 3.3 \% \\
\text { Once a week: } 2.7 \% \\
\text { At least once a month: } 3.3 \% \\
\text { Rarely: } 22.2 \% \\
\text { Never: } 64.2 \%\end{array}$ \\
\hline Frequency of cycling & $\begin{array}{c}\text { Daily: } 6.6 \% \\
\text { Few times a week: } 12.7 \% \\
\text { Once a week: } 5.8 \% \\
\text { At least once a month: } 5.8 \% \\
\text { Rarely: } 20.8 \% \\
\text { Never: } 48.4 \%\end{array}$ \\
\hline Frequency of walking & $\begin{array}{c}\text { Daily: } 43.1 \% \\
\text { Few times a week: } 28.1 \% \\
\text { Once a week: } 10.0 \% \\
\text { At least once a month: } 4.8 \% \\
\text { Rarely: } 9.1 \% \\
\text { Never: } 4.8 \%\end{array}$ \\
\hline $\begin{array}{l}\text { Primary means of traveling to the } \\
\text { most frequent destination }\end{array}$ & $\begin{array}{c}\text { Car (driver): } 48.8 \% \\
\text { Car (passenger): } 5.6 \% \\
\text { Motorcycle: } 6.6 \% \\
\text { Bus: } 4.8 \% \\
\text { Cycling: } 4.8 \% \\
\text { Walking: } 29.4 \%\end{array}$ \\
\hline $\begin{array}{l}\text { Primary factor for choosing } \\
\text { transport mode }\end{array}$ & $\begin{array}{c}\text { Cost: } 9.2 \% \\
\text { Comfort: } 41.4 \% \\
\text { Availability: } 15.5 \% \\
\text { Time: } 25.5 \% \\
\text { Environmental awareness: } 8.4 \%\end{array}$ \\
\hline $\begin{array}{l}\text { Frequency of finding oneself in } \\
\text { congestion }\end{array}$ & $\begin{array}{c}\text { Daily: } 5.8 \% \\
\text { Few times a week: } 24.1 \% \\
\text { Once a week: } 11.4 \% \\
\text { At least once a month: } 5.6 \% \\
\text { Rarely: } 41.4 \% \\
\text { Never: } 11.7 \%\end{array}$ \\
\hline
\end{tabular}


Table 3

Bicycle ownership and type of usage

\begin{tabular}{|c|c|}
\hline & Reported bicycle-related choices \\
\hline Bicycle-related norms & Respondents answers \\
\hline \multirow{2}{*}{ Bicycle ownership } & Yes: $58.3 \%$ \\
& No: $41.7 \%$ \\
\hline & Main travel mode: $6.7 \%$ \\
Way of utilising cycling & Main travel alternative: $10.8 \%$ \\
& Secondary travel alternative: $7.2 \%$ \\
& Exercise and joy: $33.3 \%$ \\
& Do not cycle: $42 \%$ \\
\hline
\end{tabular}

\section{Table 4}

Attitudes towards bicycles and cycling in general

\begin{tabular}{|c|c|c|c|}
\hline \multicolumn{4}{|c|}{$\begin{array}{l}\text { Mean support for the statements below } \\
\text { (when }-2 \text { strongly disagree and } 2 \text { strongly agree) }\end{array}$} \\
\hline \multicolumn{4}{|c|}{ Attitudes regarding the possible qualities of cycling } \\
\hline $\begin{array}{c}\text { Cycling is an } \\
\text { environmentally friendly } \\
\text { travel mode }\end{array}$ & $\begin{array}{l}\text { Cycling is a time- } \\
\text { consuming travel mode }\end{array}$ & $\begin{array}{c}\text { Cycling is an } \\
\text { inexpensive travel } \\
\text { mode }\end{array}$ & $\begin{array}{l}\text { Cycling is an unsafe } \\
\text { travel mode }\end{array}$ \\
\hline $1.83(\mathrm{SD} 0.48)$ & $-0.55(\mathrm{SD} 1.03)$ & $1.69(\mathrm{SD} 0.56)$ & $-0.1(\mathrm{SD} 1.12)$ \\
\hline Cycling improves health & $\begin{array}{c}\text { Cycling can reduce traffic } \\
\text { congestion }\end{array}$ & $\begin{array}{c}\text { Cycling is a pleasant } \\
\text { activity }\end{array}$ & $\begin{array}{l}\text { Cycling is the best } \\
\text { inner-city transport } \\
\text { alternative to car }\end{array}$ \\
\hline $1.76($ SD 0.54$)$ & $1.61(\mathrm{SD} 0.66)$ & $1.14($ SD 0.72) & $1.3(\mathrm{SD} 0.84)$ \\
\hline
\end{tabular}

\section{Table 5}

Attitudes towards promoting cycling in Drama

\begin{tabular}{|c|c|c|c|}
\hline \multicolumn{4}{|c|}{$\begin{array}{c}\text { Mean support for the statements below } \\
\text { (when -2 strongly disagree and 2 strongly agree) }\end{array}$} \\
\hline $\begin{array}{c}\text { Attitudes regarding cycling infrastructure and policies } \\
\text { should be created }\end{array}$ & $\begin{array}{c}\text { There is a need for more } \\
\text { parking facilities for } \\
\text { bicycles }\end{array}$ & $\begin{array}{c}\text { Bicycle should be the } \\
\text { object of a campaign } \\
\text { promoting sustainable } \\
\text { living }\end{array}$ & $\begin{array}{c}\text { Public bicycles should } \\
\text { be introduced in } \\
\text { Drama }\end{array}$ \\
\hline 1.71 (SD 0.63) & 1.45 (SD 0.77) & 1.34 (SD 0.87) & 1.39 (SD 0.84) \\
\hline
\end{tabular}


Table 6

Attitudes towards public bicycles and their introduction

\begin{tabular}{|c|c|c|c|}
\hline \multicolumn{4}{|c|}{$\begin{array}{l}\text { Mean support for the statements below } \\
\text { (when }-2 \text { strongly disagree and } 2 \text { strongly agree) }\end{array}$} \\
\hline \multicolumn{4}{|c|}{ Attitudes regarding bike-sharing's potential benefits } \\
\hline \multicolumn{4}{|c|}{ A public bicycle programme would be good... } \\
\hline $\begin{array}{l}\text {...for promoting a } \\
\text { greener and more human } \\
\text { friendly city }\end{array}$ & $\begin{array}{l}\ldots \text { for reducing road } \\
\text { traffic congestion }\end{array}$ & $\begin{array}{l}\text {...for complementing } \\
\text { the existing public } \\
\text { transport's services }\end{array}$ & $\begin{array}{c}\text {...for making bicycle } \\
\text { a more popular and } \\
\text { favourable travel } \\
\text { option }\end{array}$ \\
\hline $1.47(\mathrm{SD} 0.7)$ & $1.4(\mathrm{SD} 0.75)$ & $0.92(\mathrm{SD} 1.2)$ & $1.31(\mathrm{SD} 0.76)$ \\
\hline $\begin{array}{l}\text {...for promoting health } \\
\text { and wellbeing }\end{array}$ & $\begin{array}{l}\text {...for providing an } \\
\text { inexpensive city-based } \\
\text { alternative }\end{array}$ & $\begin{array}{l}\text {...for disengaging } \\
\text { people from using in a } \\
\text { daily basis their cars }\end{array}$ & $\begin{array}{c}\text { I would not like to see } \\
\text { a public bicycle } \\
\text { investment getting } \\
\text { realised }\end{array}$ \\
\hline 1.4 (SD 0.74) & $1.37(\mathrm{SD} 0.76)$ & $1.43(\mathrm{SD} 0.75)$ & $-1.34(\mathrm{SD} 0.94)$ \\
\hline
\end{tabular}

Table 7

Attitudes responding to the hypothetical introduction of bike-sharing

\begin{tabular}{|c|c|}
\hline & Reported public bicycle-related choices \\
\hline Usage expectations & Respondents answers \\
\hline $\begin{array}{c}\text { Frequency of potentially using a } \\
\text { public bicycle scheme }\end{array}$ & Daily: $10.8 \%$ \\
& Few times a week: $36.1 \%$ \\
Once a week: $15.9 \%$ \\
At least once a month: $5.6 \%$ \\
Rarely: $22.3 \%$ \\
Never: $9.2 \%$ \\
Way of utilising a & Main travel mode: $15.6 \%$ \\
public bicycle scheme & Main travel alternative: $26.4 \%$ \\
& Secondary travel alternative: $27.7 \%$ \\
Exercise and joy: $18.6 \%$ \\
Do not use: $11.7 \%$
\end{tabular}


Table 8

Ordinal regression model for bike-sharing acceptability

\begin{tabular}{|c|c|c|c|c|c|c|c|c|c|}
\hline & \multirow[b]{2}{*}{ Estimate } & \multirow[b]{2}{*}{$\begin{array}{c}\text { Std. } \\
\text { Error }\end{array}$} & \multirow[b]{2}{*}{ Wald } & \multirow[b]{2}{*}{ Df } & \multirow[b]{2}{*}{ Sig. } & \multirow[b]{2}{*}{ ExpB } & \multicolumn{2}{|c|}{$\begin{array}{c}95 \% \text { Confidence } \\
\text { Interval } \\
\end{array}$} \\
\hline & & & & & & & & $\begin{array}{l}\text { Lower } \\
\text { Bound }\end{array}$ & $\begin{array}{l}\text { Upper } \\
\text { Bound }\end{array}$ \\
\hline Threshold & Bike-sharing acceptance threshold & 1.309 & 0.602 & 4.718 & 1 & 0.030 & 3.702 & 0.128 & 2.489 \\
\hline \multirow[t]{19}{*}{ Location } & Type of usage $=$ main mode & 2.781 & 0.680 & 16.710 & 1 & 0.000 & 16.135 & 1.448 & 4.115 \\
\hline & Type of usage $=$ main alternative & 3.284 & 0.610 & 28.980 & 1 & 0.000 & 26.682 & 2.088 & 4.479 \\
\hline & Type of usage=secondary alternative & 1.596 & 0.390 & 16.739 & 1 & 0.000 & 4.933 & 0.832 & 2.361 \\
\hline & Type of usage $=$ exercise and joy & 0.759 & 0.393 & 3.737 & 1 & 0.049 & 2.136 & -0.011 & 1.529 \\
\hline & Type of usage $=$ no use & $0^{\mathrm{a}}$ & & & 0 & & 0 & & \\
\hline & Bike-sharing reducing traffic $=$ neutral $/$ negative & -2.386 & 0.374 & 40.771 & 1 & 0.000 & 10.870 & -3.118 & -1.653 \\
\hline & Bike-sharing reducing traffic $=$ positive & $0^{\mathrm{a}}$ & & & 0 & & 0 & & \\
\hline & Main reason for modal choice $=$ cost & 2.062 & 0.798 & 6.686 & 1 & 0.010 & 7.862 & 0.499 & 3.626 \\
\hline & Main reason for modal choice $=$ comfort & 1.239 & 0.464 & 7.140 & 1 & 0.008 & 3.452 & 0.330 & 2.147 \\
\hline & Main reason for modal choice $=$ availability & 1.860 & 0.604 & 9.486 & 1 & 0.002 & 6.424 & 0.676 & 3.044 \\
\hline & Main reason for modal choice $=$ time & 0.759 & 0.487 & 2.432 & 1 & 0.119 & 2.136 & -0.195 & 1.714 \\
\hline & Main reason for modal choice $=$ environment & $0^{\mathrm{a}}$ & & & 0 & & 0 & & \\
\hline & Gender=female & 0.699 & 0.303 & 5.335 & 1 & 0.021 & 2.012 & 0.106 & 1.293 \\
\hline & Gender $=$ male & $0^{\mathrm{a}}$ & & & 0 & & 0 & & \\
\hline & Age $=60$ and over & 1.842 & 0.761 & 5.855 & 1 & 0.016 & 6.309 & 0.350 & 3.335 \\
\hline & Age $=50-59$ & 1.352 & 0.493 & 7.518 & 1 & 0.006 & 3.865 & 0.386 & 2.319 \\
\hline & Age $=40-49$ & 0.551 & 0.363 & 2.306 & 1 & 0.129 & 1.735 & -0.160 & 1.263 \\
\hline & Age $=30-39$ & 1.089 & 0.430 & 6.397 & 1 & 0.011 & 2.971 & 0.245 & 1.932 \\
\hline & Age $=29$ or younger & $0^{\mathrm{a}}$ & & & 0 & & 0 & & \\
\hline
\end{tabular}

$\mathrm{N}=640$, Model chi-square $=156.100 ; \mathrm{p}<0.01,-2 \log$ likelihood $=224.219$, Nagelkerke Pseudo $\mathrm{R}^{2}=0.400$.

a. This parameter is set to zero because it is the base category (the reference for comparisons). 


\section{Figures}

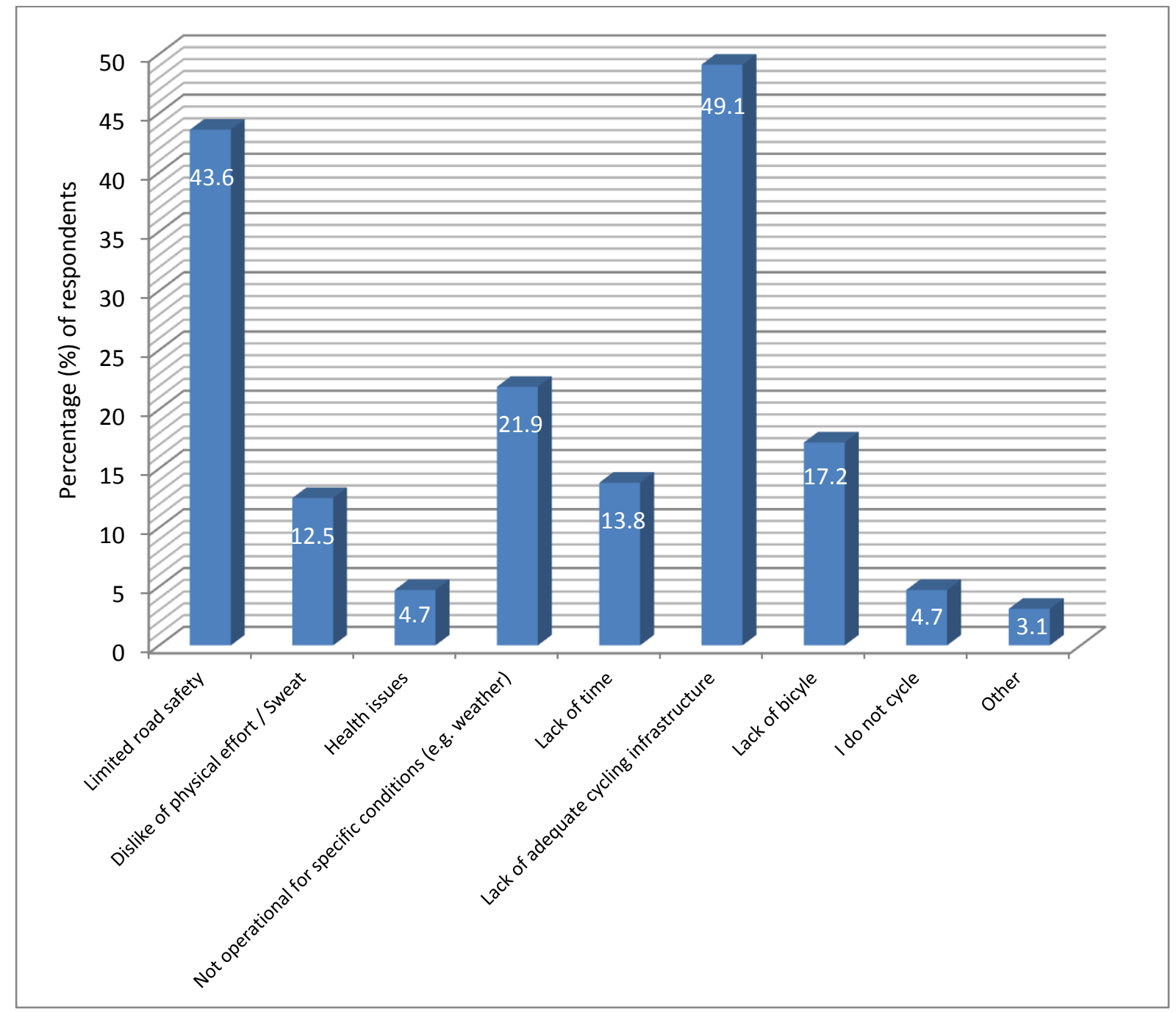

Fig. 1. Reasons for not cycling and not being willing to eventually bike-share 